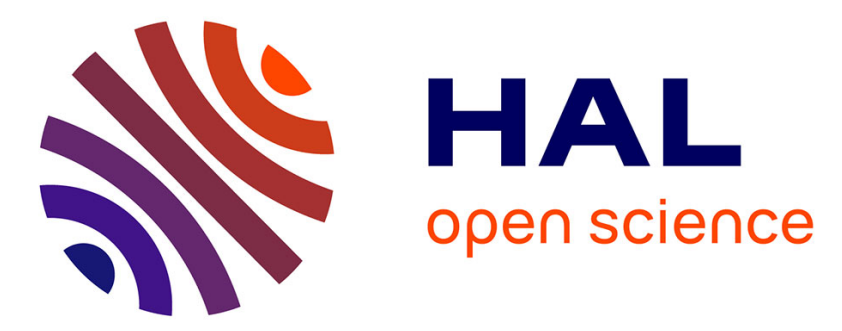

\title{
Environmental and exergetic life cycle assessment of incineration- and gasification-based waste to energy systems in China
}

\author{
Yuanjun Tang, Jun Dong, Guoneng Li, Youqu Zheng, Yong Chi, Ange \\ Nzihou, Elsa Weiss-Hortala, Chao Ye
}

\section{To cite this version:}

Yuanjun Tang, Jun Dong, Guoneng Li, Youqu Zheng, Yong Chi, et al.. Environmental and exergetic life cycle assessment of incineration- and gasification-based waste to energy systems in China. Energy, 2020, 205, pp.1-10/118002. 10.1016/j.energy.2020.118002 . hal-02863924

\section{HAL Id: hal-02863924 https://imt-mines-albi.hal.science/hal-02863924}

Submitted on 17 Jul 2020

HAL is a multi-disciplinary open access archive for the deposit and dissemination of scientific research documents, whether they are published or not. The documents may come from teaching and research institutions in France or abroad, or from public or private research centers.
L'archive ouverte pluridisciplinaire HAL, est destinée au dépôt et à la diffusion de documents scientifiques de niveau recherche, publiés ou non, émanant des établissements d'enseignement et de recherche français ou étrangers, des laboratoires publics ou privés. 


\title{
Environmental and exergetic life cycle assessment of incineration- and gasification-based waste to energy systems in China
}

\author{
Yuanjun Tang a, c, d, Jun Dong ${ }^{b, d}$, Guoneng Li ${ }^{a}$, Youqu Zheng ${ }^{a,}{ }^{*}$, Yong Chi ${ }^{c}$, \\ Ange Nzihou ${ }^{\mathrm{d}}$, Elsa Weiss-Hortala ${ }^{\mathrm{d}}$, Chao Ye ${ }^{\mathrm{a}}$ \\ a Department of Energy and Environment System Engineering, Zhejiang University of Science and Technology, Hangzhou, 310023, China \\ ${ }^{\mathrm{b}}$ Key Laboratory of Recycling and Eco-treatment of Waste Biomass of Zhejiang Province, Zhejiang University of Science and Technology, Hangzhou, 310023, \\ China \\ c State Key Laboratory of Clean Energy Utilization, Zhejiang University, Hangzhou, China \\ d IMT Mines Albi-Carmaux, RAPSODEE CNRS UMR-5302, Campus Jarlard, F-81013, Albi Cedex 09, France
}

Keywords:

Life cycle assessment

Exergetic life cycle assessment

Incineration

Gasification

Environmental impact

Cumulative exergy consumption

\begin{abstract}
A B S T R A C T
The clean and efficient energy production from municipal solid waste (MSW) is highly desirable due to increasing energy demand and environmental concerns. In this study, four incineration- (S1) and gasification-based (S2 with combustion boiler, S3 with gas turbine/combined cycle and S4 with internal combustion engine) MSW treatments were compared using methods of environmental life cycle assessment (LCA) and exergetic life cycle assessment (ELCA). LCA was applied to measure the environmental performances and ELCA was supplemented to reflect the thermodynamics efficiencies. Afterwards, cumulative degree of perfection (CDP) and abatement exergy (AbatCExC) efficiency of the considered systems were also calculated to determine the imperfection and environmental sustainability of the processes. Results showed that gasification-based systems were effective to mitigate the environmental impacts of acidification, nutrient enrichment, and photochemical ozone formation potential, but caused higher global warming impacts. The S3 system exhibited the best performance from both environmental and exergetic perspective, due to its high net efficiency of electricity generation and low exhaust emission into air. Results from ELCA indicated that the rest two gasification-based systems (S2 and S4) were inefficient as compared to MSW direct incineration, mainly due to auxiliary energy consumption for MSW pretreatment and more conversion steps. The CDP and AbatCExC of the systems in descending order was expressed as S3 system $>$ S1 system > S2 system > S4 system.
\end{abstract}

\section{Introduction}

The generation and treatment of municipal solid waste (MSW) has become an unavoidable and serious challenge in recent years. Among different MSW treatment technologies, incineration is a well-proven method to achieve both waste mass/volume reduction and energy recovery. MSW incineration was developed rapidly and used for energy production in the past few decades around the world. However, with this technique the hazardous pollutants, such as dioxins and heavy metals released from MSW incinerators may cause severe environmental burden [1]. Additionally, the overall efficiency for power generation of a MSW incineration plant is very

\footnotetext{
* Corresponding author.

E-mail address: zyq888@zust.edu.cn (Y. Zheng).
}

low at approximately $20 \%$ due to the formation of hydrogen chloride in the flue gas [2]. In order to avoid corrosive effect of high temperature to the devices, temperature and pressure of the generated steam in MSW incineration plants are strictly controlled. Consequently, MSW incineration setup is facing resistance by the public in some areas of China. Therefore, the demand for developing clean and efficient energy production from MSW attracts increasingly interests.

MSW gasification is believed a promising alternative to achieve clean and efficient energy production as well as safe disposal of MSW. Through gasification, MSW is first converted to high-valueadded intermediate products as producer gas, tar and char, which has applications in more efficient and clean routes, such as gas turbine/combined cycle or used as feedstock to produce chemicals [3]. MSW gasification is by no means a novel concept rather studied and published from the recent past years [4-7]. However, its 
commercial applications in China or other developing countries are not yet widespread. Therefore, a comprehensive evaluation of gasification-based waste to energy (WtE) systems from both environmental and energy conversion perspectives are of great importance before it is launched.

The Life cycle assessment (LCA) is a widely acknowledged evaluation method that compares the environmental impacts of products, service, or systems from "cradle to grave" throughout the life cycle [8]. LCA has now been successfully applied to waste thermal treatment technologies majorly waste incineration with or without energy recovery [9-11]. While only few studies were related with gasification-based WtE technologies. Arena et al. conducted life cycle comparison of environmental performances from combustion- and gasification-based WtE technologies, indicating that moving grate incineration system behaved better than gasification-based system [12]. Evangelisti et al. also evaluated the environmental impacts caused by both incineration and "twostage" WtE conversions using LCA method and concluded that twostage gasification-based process had a significantly better performance [13].

However, when LCA is applied to thermal conversion systems, it is not proven to be efficient in identifying thermodynamic irreversibility and energy degradation of processes, since it considers only "quantity" of energy forms but not "quality" [14]. Exergybased approaches are commonly used as they consider both quantity and quality of energy carriers as proved by first and second law of thermodynamics [15]. Recently, exergetic life cycle assessment (ELCA) is proposed and developed based on the combination of LCA and exergy analysis [16,17]. Through ELCA, all the input, output energy and material flows, especially for non-energetic resources, are quantified and compared by summarizing the total exergy amount. ELCA can be recognized as a part of LCA studies that reflects the impact category of resources depletion of the target systems. Moreover, ELCA can also be applied to evaluate energy consumption for the elimination of released pollutants. However, only limited ELCA studies were conducted on MSW gasificationbased thermal treatments.

The aim of this study was to evaluate the environmental impacts and thermodynamic efficiencies of incineration- and gasificationbased WtE systems. Four WtE systems were modeled and compared using the methods of environmental LCA and exergetic LCA. Environmental LCA was applied to compare environmental impacts and ELCA was used to analyze the system's thermodynamic efficiency. This study was aimed at identifying a clean and efficient energy production system from MSW thermal conversion, and providing scientific guidance for exploring sustainable waste management methods.

\section{Materials and methods}

In this study, both LCA and ELCA processes were conducted to evaluate and compare the environmental impact and resource consumption of the proposed system. As guided by the International Organization for Standardization (standards 14040 series) [18], the framework of a LCA study was composed of four steps: goal and scope definition, inventory analysis, impact assessment, and interpretation. ELCA is recognized as a part of LCA and the general framework of both methods were considered identical. More detailed information about the methodology used in the manuscript can be found in our previous publications $[19,20]$.

\subsection{Incineration- and gasification-based WtE systems}

System boundary and flow charts of the considered system were illustrated in Fig. 1. The evaluation started with collection of MSW into WtE plant, it ignored the upstream waste collection and transportation stages. After this, further stages were MSW pretreatment (optional), MSW incineration or gasification, electricity generation, and finally residues disposal. The direct incineration of MSW was considered as the baseline system (S1). For the gasification-based WtE systems, 3 typical downstream electricity generation technologies were investigated by converting the producer gas in a boiler/steam turbine (S2), gas turbine combined cycle (gas turbine/CC) (S3), or internal combustion engine (S4). Thus, 4 systems were proposed and evaluated to compare both the environmental burden and energetic performances. Furthermore, all the input and output materials/energy flows were considered in this assessment. The electricity generated from the proposed systems will be used to substitute the same amount of electricity generated from Chinese national electricity grid. Additionally, indirect emissions related to raw energy and materials acquisition were also evaluated.

\subsection{MSW characteristics and pretreatment}

The data inventory, including all inputs and outputs were calculated using functional unit defined as "1000 kg of treated MSW". The typical values for characterization of MSW in Hangzhou, China, were specified in Table 1 [20].

Due to the high moisture content of raw MSW in China, pretreatment of raw MSW for gasification-based WtE systems was essential to achieve the effective results through gasification [21]. Therefore, the moisture content of the received MSW was reduced to around 10\% through thermal drying. The thermal heat for MSW drying was acquired either from steam extraction through steam turbine (S2) or sensible heat recovery from raw syngas purification and cooling down (S3 and S4). Thus, approximately $1060 \mathrm{MJ}$ of heat was required to lower the moisture content for one tonne of raw MSW. Additionally, before feeding into the gasifier, MSW was mechanically shredded to enhance the gasification process. The energy consumed for crushing of one tonne of MSW was equal to $100 \mathrm{kWh}$ of electricity according to Kourkoumpas et al. [22].

\subsection{Description of the proposed systems}

\subsubsection{S1: MSW direct incineration and steam turbine}

S1 system was referred to MSW direct incineration and steam turbine system as shown in Fig. 1. A commercial waste incineration power plant, which is located in Hangzhou with a treatment capacity of 1200.0 tons/day was adopted to estimate the input and output flows. MSW was directly incinerated as it was received, and the heating value was used to generate electricity. In order to control the emission of air pollutants, flue gas treatment facilities equipped with semidry-dry scrubber, active carbon adsorption, and bag house filters, were used [23]. The air emission from the considered system should meet the expected regulation requirements of China. While, the solid residues that were produced during processes were collected and pretreated in the plant and then sent to landfill site. The overall power generation efficiency was set to be $22.5 \%$ based on MSW lower heating value. It was assumed that $20.0 \%$ of the total generated electricity was consumed as auxiliary power in the power-plant $[20,24]$.

\subsubsection{Data used for gasification-based technologies (S2, S3, and S4)}

The qualitative analysis of life cycle of inventory data determines directly the effectiveness of an LCA or ELCA. However, due to the limited commercial applications of gasification-based WtE in China, detailed operational data was hardly available. Therefore, the inventory data was mainly summarized from literature, standard regulations and operational reports. Thermal conversion 


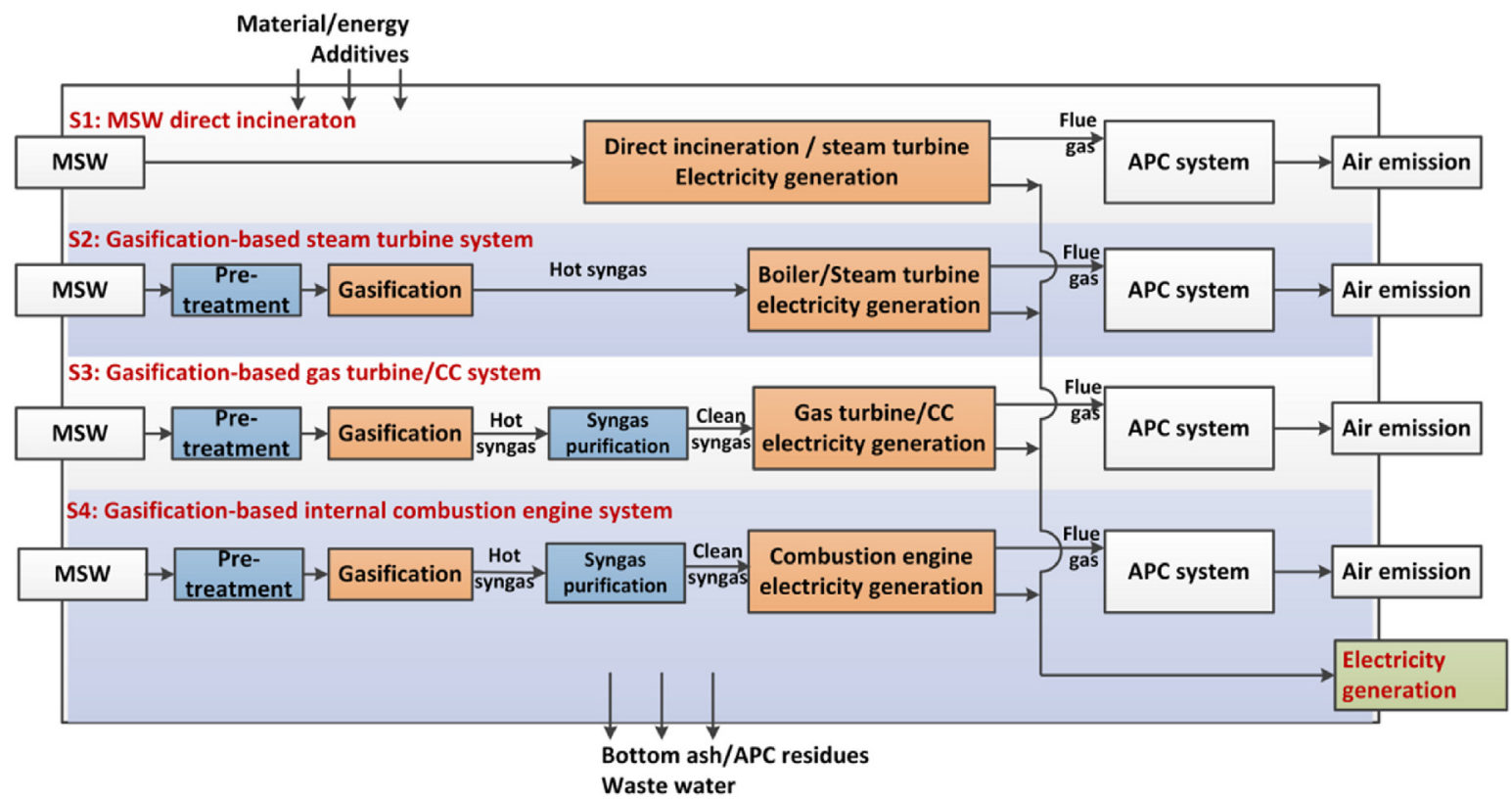

Fig. 1. System boundary and flow charts of the considered systems (Gas turbine/CC system represents Gas turbine/combined cycle system).

Table 1

Characteristics of MSW.

\begin{tabular}{|c|c|c|c|c|c|c|c|}
\hline \multicolumn{8}{|c|}{ MSW Characteristics (wt. \%, as received basis) } \\
\hline Carbon & Hydrogen & Oxygen & Nitrogen & Sulfur & Moisture & Ash & Lower heating value $(\mathrm{MJ} / \mathrm{kg})$ \\
\hline 25.0 & 4.0 & 12.1 & 0.8 & 0.1 & 34.0 & 24.0 & 9.8 \\
\hline
\end{tabular}

efficiencies of gasification process (typically expressed as cold gas efficiency and hot gas efficiency) are the most important parameter determines the overall system performance. Therefore, Table 2 summarized results of typical values of cold and hot gas efficiencies during waste and biomass gasification processes from open literature based on experimental trials and simulation works [20,25-36]. Accordingly, the reported cold gas efficiency ranged from 53.0 to $92.0 \%$; therefore an average value of $70.0 \%$ was adopted in this evaluation. Similarly, a hot gas efficiency of $90.0 \%$ was also estimated for S2, where the produced hot syngas (including tar compounds) was directly combusted in a secondary chamber without purification and cooling down. Regarding to air pollution control (APC) systems, the same configuration as aforementioned in MSW direct incineration system was assumed for gasification-based WtE systems (semidry-dry scrubber, active carbon adsorption, and bag house filter).

\subsubsection{S2: currently available gasification-based hot syngas direct} combustion and steam turbine (Ga-HSC) system

Currently, several gasification-based two-stage WtE technologies were found to be used in commercial applications, for example the gasification-based WtE plants that is operated by English company Ener-G and by Japanese company Ebara [34]. Within their schemes, waste was not directly burned, but converted into combustible product gas through gasification prior to be combusted, i.e. waste was subjected to a "two step" oxidation process. This would enable a better control of homogeneous gas-gas oxidation in the second combustion chamber and allowed the reduction of exhausted flue gas heat loss [37,38], resulting in an increase of the overall efficiency for electricity generation.

Table 2

Literature survey of cold and hot gas efficiencies during waste and biomass gasification.

\begin{tabular}{|c|c|c|c|c|c|c|}
\hline Feedstock & Scale & LHV of feed MJ/kg & Cold gas efficiency $\%$ & Hot gas efficiency $\%$ & Gasifier type & \\
\hline Lignite, wood, mixtures & $10.0 \mathrm{kWe}$ & $16.4-19.9$ & $65.0-71.6$ & - & Down-draft & [25] \\
\hline Woody biomass & $10.0 \mathrm{kWth}$ & $16.3-18.7$ & $65.0-80.0$ & - & Down-draft & [26] \\
\hline MSW & - & 16.4 & $71.6-74.8$ & - & Simulation & [27] \\
\hline Oak tree wood chips & $26.5-27.8 \mathrm{~kg} / \mathrm{h}$ & 19.6 & $59.5-65.2$ & $69.90-77.10$ & Down- draft & [28] \\
\hline Loblolly pine & - & $20.2(\mathrm{HHV})$ & $56.1-67.5$ & $67.51-83.83$ & Fluidized bed & [29] \\
\hline Wood biomass & 10.0 MWe & 18.1 & 84.0 & - & Simulation & [30] \\
\hline SRF & $400.0 \mathrm{kWe}$ & $18.6-21.3$ & $53.0-61.0$ & - & Fluidized bed & [31] \\
\hline Cane bagasse & $50.0 \mathrm{kWe}$ & 17.6 & $77.0-92.0$ & - & Down-draft & [32] \\
\hline MSW & Review paper & - & $50.0-80.0$ & - & - & [33] \\
\hline MSW & Review paper & - & $65.2-82.5$ & $97.9-102.4$ & Grate/fluidized bed & [34] \\
\hline Cassava rhizome & Bench scale & $14.9(\mathrm{HHV})$ & $69.0-81.0$ & $72.0-90.0$ & Down-draft & [35] \\
\hline Woody biomass & $12.5 \mathrm{~kg} / \mathrm{h}$ & - & $71.7-73.8$ & - & Fluidized bed & [36] \\
\hline MSW & - & - & 70.0 & 90.0 & LCA study & [20] \\
\hline
\end{tabular}


Therefore, S2 system represented the gasification-based hot syngas direct combustion and steam turbine system (Ga-HSC) as presented in Fig. 1, but waste pretreatment was required in S2. The energy consumed for waste thermal drying was obtained through the low-quality steam extraction from the steam turbine. After gasification step, high temperature raw syngas (including tar) was combusted directly in a second combustion chamber to generate steam. The generated steam was then used to derive a steam turbine for electricity production. Solid residues produced were collected, pretreated and then sent to landfill site. Electricity generation efficiency of the Ga-HSC system was considered to be $27.8 \%$ according to Morris et al. [24], and $20.0 \%$ of the generated electricity was consumed in the plant.

\subsubsection{S3: gasification-based purified syngas to gas turbine/ combined cycle (Ga-PStoGT/CC) system}

Generally, one potential advantage of gasification technology over waste direct incineration is the production of high-valueadded intermediate products that could be used in cleaner and more efficient energy conversion devices. Thus, high efficiency utilization of produced gas (for example gas turbine combined cycle) were also proposed and evaluated in this study, even though their commercial applications are still under progress.

S3 system was referred to the gasification-based purified syngas to gas turbine/combined cycle (Ga-PStoGT/CC) system as illustrated in Fig. 1. For Ga-PStoGT/CC system, the produced raw syngas was first cooled down and purified for the removal of tar-containing compounds and particulate contaminants to meet the strict purification requirements of a gas turbine. Under such conditions, energy for MSW thermal drying was recovered from the sensible heat of raw syngas cooling down. After being purified, cleaned syngas was fed into the combustion chamber of a gas turbine in order to generate electricity. The exhausted gas from gas turbine outlets was then fed into a heat recovery boiler to generate steam and then to drive a steam turbine. In this way, a higher overall electricity generation efficiency can be achieved through this process. The power generation efficiency of gas turbine/combined cycle system was considered to be $35.5 \%$ according to Morris et al. [24]. Similarly, it was assumed that $20 \%$ of the total generated electricity was utilized in plant consumption. Actually, it is known that the auxiliary energy was higher in S3 system as compared to S1 and S2, since more electricity was consumed in syngas purification stage. However, due to the lack of actual operation data, the same percentage of insitu electricity consumption, i.e. 20.0\%, was considered for all the systems. APC system and the treatment of solid residues were similar to S1 and S2.

\subsubsection{S4: gasification-based purified syngas to internal combustion engine (Ga-PStoICE) system}

S4 system represented to the gasification-based purified syngas to internal combustion engine system (Ga-PStoICE) as exhibited in Fig. 1. Similar to S3, there was same stage of raw syngas purification and the recovered sensible heat was used for MSW drying. The purified syngas was then fed into an internal combustion engine to generate electricity, whose efficiency was considered to be $25 \%$ as explained by Belgiorno et al. [39], with $20.0 \%$ of the total generated electricity used in the plant. The same APC system and solid residues treatment methods were adopted in this system.

\subsection{Air emissions from each system}

Chinese national regulation emission standards were used to estimate the air emission levels in order to make parallel comparisons of the considered system. Thus, assumptions have been made that all the air emissions from the considered systems strictly meet the Chinese national standards. Detailed information about the regulation emission data was presented in Table 3. It is also preferred to use the actual data in the analysis in place of the regulation emission standards, as the data become available.

\subsection{Residues final disposal}

The amount of solid residues was estimated to be $220.0 \mathrm{~kg}$ for incineration-based system and $242.0 \mathrm{~kg}$ for gasification-based WtE systems according to Arena et al. [12]. With regard to APC residues, solidification and stabilization was conducted before the residues were sent to landfill site. However, due to the lack of available data, downstream emission in landfill sites was not considered, and only the transportation of solid residues was analyzed. This assumption was considered reasonable, since it was applied consistently across the systems. The corresponding distance from WtE plants to landfill site was considered identical for each system and set to be $50.0 \mathrm{~km}$.

\subsection{Life cycle environmental impact assessment}

Environmental impact assessment was calculated according to Danish EDIP 97 method [42]. Four environmental impacts were quantified during this study, including global warming potential $(G W)$, acidification potential (AC), nutrient enrichment potential (NE), and photochemical ozone formation potential (POF). The characterization factors were adopted using GaBi 7.0 software as the EU average value.

\subsection{Exergetic life cycle assessment}

The ELCA method was proposed and developed by combining the concept of exergy analysis and environmental LCA. Generally, ELCA and LCA share the same framework, their goal and scope definition steps were identical. In this study, cumulative exergy consumption (CExC) was applied to compare ELCA efficiencies. CExC can be defined as "the total amount of exergy consumed to produce the target material or energy in its entire production chain". It would record the natural resources consumption and depletion from the exploitation of most primary stage of the original minerals. Therefore, CExC can be used as resource accounting tool that has role in summarizing and comparing the total CExC of all input and output streams respectively.

In this study, CExC efficiency ( $\eta_{\text {CExC }}$ ) was defined and calculated, which expresses the ratio of the total CExC of the output products and the input resources as evident in Eq. (1) [19,43]:

$\eta_{\text {CExC }}=\frac{\left(\sum_{\mathrm{i}} \mathrm{O}_{\mathrm{i}}\right)_{\mathrm{CExC}}}{\left(\sum_{\mathrm{j}} \mathrm{I}_{\mathrm{j}}\right)_{\mathrm{CExC}}}=\frac{\left(\mathrm{O}_{\text {electricity }}\right)_{\mathrm{CExC}}}{\left(\mathrm{I}_{\mathrm{MSW}}+\mathrm{I}_{\text {electricity }}+\mathrm{I}_{\text {diesel oil }}+\mathrm{I}_{\text {limestone }}\right)_{\text {CExC }}}$

where, $\eta_{\text {CExC }}$ is the defined CExC efficiency, I represents the input flows, including MSW, auxiliary electricity, diesel oil and limestone; and $\mathrm{O}$ refers to the output flows, mainly electricity.

In order to evaluate the degree of thermodynamic imperfections of the considered thermal conversion systems, cumulative degree of perfection (CDP) was proposed and defined as the ratio of chemical exergy content of the products to the total CExC of the input energy and materials as presented in Eq. (2) [43,44]:

$\mathrm{CDP}=\frac{\mathrm{e}_{\mathrm{x}, \text { electricity }}}{\left(\mathrm{I}_{\mathrm{MSW}}+\mathrm{I}_{\text {electricity }}+\mathrm{I}_{\text {diesel oil }}+\mathrm{I}_{\text {limestone }}\right)_{\text {CExC }}}$

where, CDP is cumulative degree of perfection of the system; 
Table 3

Regulation emission standards adopted in this study.

\begin{tabular}{|c|c|c|c|c|}
\hline Unit: $\mathrm{mg} / \mathrm{Nm}^{3}$ & $\mathrm{~S} 1$ :Incinerator ${ }^{\mathrm{a}}$ & S2:Gas boiler-steam turbine ${ }^{b}$ & $\begin{array}{l}\text { S3:Gas turbine/ } \\
\text { CC }^{\text {b }}\end{array}$ & S4:Internal combustion engine ${ }^{b}$ \\
\hline $\mathrm{CO}^{\mathrm{c}}$ & 80.0 & 80.0 & 80.0 & 80.0 \\
\hline $\mathrm{SO}_{2}$ & 80.0 & 35.0 & 35.0 & 35.0 \\
\hline $\mathrm{NO}_{\mathrm{x}}$ & 250.0 & 100.0 & 50.0 & 50.0 \\
\hline $\mathrm{HCl}^{\mathrm{d}}$ & 50.0 & 50.0 & 0 & 0 \\
\hline PM & 20.0 & 5.0 & 5.0 & 5.0 \\
\hline Dioxins (ng I-TEQ/ $\left.\mathrm{Nm}^{3}\right)^{\mathrm{c}}$ & 0.1 & 0.1 & 0.1 & 0.1 \\
\hline
\end{tabular}

$\mathrm{e}_{\mathrm{x}, \mathrm{elcticity}}$ represents the chemical exergy of the produced electricity.

The exergy consumption for the treatment of emissions to the environment should also be taken into account in ELCA analysis. Abatement exergy (AbatEx) was thus defined as "the internal exergy lose caused by the abatement of air emissions to an accepted limit for environment" [45]. It was calculated by measuring the amount of the emissions and the exergy consumption for the abatement of them. In this study, the abatement exergy of $\mathrm{CO}_{2}$ (fossil source), $\mathrm{SO}_{2}$ and $\mathrm{NO}_{\mathrm{x}}$ were considered whose values were found to be $5.9,57.0$ and $16.0 \mathrm{MJ} / \mathrm{kg}$, respectively. The reason for limiting the calculation of the abatement exergy for these air emissions was mainly due to the lack of available data in literature [46].Under such circumstance, ELCA can be applied to measure both energy conversion efficiency and environmental performances. Thus, AbatCExC efficiency ( $\left.\eta_{\text {AbatCExC }}\right)$ was proposed and evaluated, where the abatement exergy was subtracted from the output CExC flows to represent the internal exergy lose caused by emissions as seen in Eq. (3) $[43,44]$ :

$$
\begin{aligned}
\eta_{\text {AbatCExC }} & =\frac{\left(\sum_{\mathrm{i}} \mathrm{O}_{\mathrm{i}}\right)_{\text {CExC }}-\text { AbatEx }}{\left(\sum_{\mathrm{k}} \mathrm{I}_{\mathrm{k}}\right)_{\mathrm{CExC}}} \\
& =\frac{\left(\mathrm{O}_{\text {electricity }}\right)_{\mathrm{CExC}}-\text { AbatEx }}{\left(\mathrm{I}_{\mathrm{MSW}}+\mathrm{I}_{\text {electricity }}+\mathrm{I}_{\text {diesel }}+\mathrm{I}_{\text {limestone }}\right)_{\mathrm{CExC}}}
\end{aligned}
$$

where, AbatEx represents abatement exergy required for treating the released air emissions.

\section{Inventory analysis}

Based on the collected data, the key parameters and assumptions, the inventory data (the input and output materials/energy flows) for each system was expressed as per functional unit as shown in Table 4. Electricity structure was taken from the average values of Chinese electricity mix (63.0\% fossil fuel, $16.9 \%$ hydropower, $10.4 \%$ wind power, $7.2 \%$ solar power and $2.5 \%$ nuclear power). The inventory data of background system was mainly adopted from GaBi 7.0 database. Based on Table 4, the CExC and abatement exergy library of materials/energy flows and air emissions were presented in Table 5.

\section{Results and discussion}

\subsection{Environmental life cycle assessment results}

Fig. 2 illustrates the characterization of environmental impacts resulted from the impact categories of global warming potential $(\mathrm{GW})$, acidification potential (AC), nutrient enrichment potential
(NE), and photochemical ozone formation potential (POF). Emissions and their contribution towards the characterization was divided into four different life cycle stages: impacts caused by the acquisition of raw energy/materials, direct emissions to the environment, avoided impacts resulted from electricity generation, and impacts caused by final residues disposal. Additionally, the net impacts was also calculated and presented.

In general, gasification-based WtE systems (S2, S3 and S4) caused the lower environmental burden as compared to MSW direct incineration (S1) except for the impact category of GW. As presented in Fig. 2, the impact category of GW caused by S2 and S4 system reached to the values of $107.9 \mathrm{~kg} \mathrm{CO}$-equivalent and $129.2 \mathrm{~kg} \mathrm{CO}$-equivalent, and was found to be much higher than $\mathrm{S} 1$ system ( $56.4 \mathrm{~kg} \mathrm{CO}$ - equivalent). The reason was mainly attributed to the additional consumption of electricity and diesel for the pretreatment stage of MSW. Among the four systems, the GaPStoGT/CC (S3) system exhibited the best environmental behavior on all the considered impact categories. Additionally, it was also observed about impact categories of $\mathrm{AC}$, NE and POF, negative impacts or environmental savings would always been obtained from gasification-based systems (except for POF from S2), thus leads to environmental benefits by implementing gasification-based WtE technologies.

Among the four different life cycle stages of the impact contributors, impact caused by final residues disposal were relatively small, accounting for less than $1.5 \%$. This was mainly attributed to the assumption that air emissions and leachates from solid residues landfill were not considered. In final residues disposal stage, only the transportation of the solid residues to landfill site was evaluated. Impacts generated from raw energy/materials acquisition ranged from $0.3 \%$ to $1.8 \%$ for incineration-based system (S1), however, the impact increased significantly to the range between $14.5 \%$ and $28.9 \%$ for gasification-based systems (S2, S3 and S4). The main reason was the consumption of additional energy for raw MSW pre-treatment step before gasification process (as aforementioned, $100 \mathrm{kWh}$ of electricity for one tonne of MSW). There was an obvious increase of this part of environmental impacts that leads to lower performance of the category of GW under gasification-based conditions. Direct emission occupied $43.2 \%-$ $70.7 \%$ of the total impact for S1, but accounted for $5.0 \%-41.7 \%$ for gasification-based systems. Negative impacts were obtained from electricity generation and this part of impacts accounted for the range between $28.4 \%$ and $76.5 \%$ for all the considered impact categories.

Through currently available technologies (S1 and S2), environmental savings was obtained from the impact categories of AC, NE, and POF of Ga-HSC system. The use of waste gasification and hot syngas direct combustion method to generate electricity approximately saves $138.3 \%, 103.5 \%$ and $36.8 \%$ of AC, NE and POF impacts 
Table 4

Data inventory for each system (based on $1000 \mathrm{~kg}$ MSW treated).

\begin{tabular}{|c|c|c|c|c|c|}
\hline Parameter & Unit & S1: Direct incineration & S2: Ga-HSC & S3: Ga-PStoGT/CC & S4: Ga-PStoICE \\
\hline \multicolumn{6}{|l|}{ Input } \\
\hline MSW & $\mathrm{kg}$ & 1000.0 & 1000.0 & 1000.0 & 1000.0 \\
\hline Electricity ${ }^{a}$ & kWh & 0 & 100.0 & 100.0 & 100.0 \\
\hline Diesel $^{\mathrm{b}}$ & $\mathrm{L}$ & 4.9 & 7.7 & 7.7 & 7.7 \\
\hline Limestone & $\mathrm{kg}$ & 10.0 & 6.5 & 4.3 & 4.3 \\
\hline \multicolumn{6}{|l|}{ Output } \\
\hline Electricity & kwh & 490.0 & 497.2 & 575.0 & 405.0 \\
\hline Heat & MJ & & & 502.7 & 502.7 \\
\hline \multicolumn{6}{|l|}{ Emissions } \\
\hline $\mathrm{CO}_{2}$, fossil & $\mathrm{kg}$ & 331.3 & 331.4 & 331.4 & 331.4 \\
\hline $\mathrm{CO}$ & $\mathrm{kg}$ & 0.4 & 0.3 & 0.2 & 0.2 \\
\hline $\mathrm{SO} 2$ & $\mathrm{~kg}$ & 0.4 & 0.1 & 0.1 & 0.1 \\
\hline NOx & $\mathrm{kg}$ & 1.3 & 0.4 & 0.1 & 0.1 \\
\hline $\mathrm{HCl}$ & $\mathrm{kg}$ & 0.3 & 0.2 & 0 & 0 \\
\hline Dust & $\mathrm{kg}$ & 0.1 & 0 & 0 & 0 \\
\hline Dioxins & kg I-TEQ & $5.1 \mathrm{E}-07$ & 3.7E-07 & $2.5 \mathrm{E}-07$ & $2.5 \mathrm{E}-07$ \\
\hline
\end{tabular}

a energy consumed for the pretreatment of MSW.

b material consumption for the transportation of solid residues.

Table 5

Cumulative exergy consumption (CExC) and abatement exergy (AbatEx) of material/energy flows and air emissions.

\begin{tabular}{|c|c|c|c|c|c|c|}
\hline & & CExC & Chemical exergy & Abatement exergy & Unit & Reference \\
\hline \multirow[t]{3}{*}{ Materials } & MSW & & $11.1^{\mathrm{a}}$ & & $\mathrm{MJ} / \mathrm{kg}$ & \\
\hline & Diesel & 53.2 & & & $\mathrm{MJ} / \mathrm{kg}$ & [47] \\
\hline & Limestone & 5.7 & & & $\mathrm{MJ} / \mathrm{kg}$ & [47] \\
\hline \multirow[t]{2}{*}{ Energy } & Electricity & 12.4 & 3.6 & & $\mathrm{MJ} / \mathrm{kWh}$ & {$[47,48]$} \\
\hline & Heat & 2.0 & 0.4 & & $\mathrm{MJ} / \mathrm{MJ}$ & [47] \\
\hline \multirow[t]{3}{*}{ Emissions ${ }^{b}$} & $\mathrm{CO}_{2}$ & & & 5.9 & $\mathrm{MJ} / \mathrm{kg}$ & {$[19,49]$} \\
\hline & $\mathrm{SO}_{2}$ & & & 57.0 & $\mathrm{MJ} / \mathrm{kg}$ & [19] \\
\hline & $\mathrm{NO}_{\mathrm{x}}$ & & & 16.0 & $\mathrm{MJ} / \mathrm{kg}$ & [19] \\
\hline
\end{tabular}

${ }^{a}$ CExC for MSW was not considered, since the LCA and ECLA studies started from MSW entering WtE plants in this work, therefore only its exergy (11.08 MJ/kg) was considered.

${ }^{\mathrm{b}}$ Due to the lack of available data, only the abatement exergy of the gaseous emissions $\mathrm{CO}_{2}, \mathrm{SO}_{2}$ and $\mathrm{NO}_{\mathrm{x}}$ were considered.

respectively. This was because of the "two-stage" conversion configuration of $\mathrm{S} 2$, therefore, direct emissions (such as $\mathrm{SO}_{\mathrm{x}}, \mathrm{NO}_{\mathrm{x}}$ and PMs) from S2 to the environment was much lower than that of S1 as shown in Table 2, thus a considerable amount of environmental impacts was avoided. Also, as explained earlier, higher electricity generation from S2 due to higher power efficiency, it contributed more environmental credits on the impacts of $\mathrm{AC}, \mathrm{NE}$ and POF.

The parallel comparison of gasification-based WtE systems with different downstream electricity generation devices (S2, S3, and S4), the S3 Ga-PStoGT/CC system was the preferred option as depicted through assessment analysis. Environmental performance of the considered systems was varied in descending order, that was S3: Ga-PStoGT/CC system > S2: Ga-HSC system > S4: Ga-PStoICE system (">" means the former system is superior to the later one). The overall electricity generation efficiencies and direct emission were responsible for these differences. It should be noted that due to the purification step of produced syngas, the emissions from S3 and S4 were found to be lower than that of S2. Therefore, the impacts from direct emission of S3 and S4 were lower than that of S2. Nevertheless, due to the lack of convincing data, the auxiliary costs and emissions from the syngas purification stage were not taken into consideration. However, this simplification was seemingly reasonable, since this part was considered to be negligible as compared to the whole WtE system.

\subsection{Exergetic life cycle assessment results}

As based on exergetic life cycle assessment (ELCA) results, the cumulative exergy consumption (CExC) efficiencies and cumulative degree of perfection (CDP) of considered systems were illustrated in Fig. 3. CExC efficiency ( $\eta_{\mathrm{CExC}}$ ) of the considered systems in descending order was expressed as the Ga-PStoGT/CC (S3) system of $64.4 \%>$ the direct incineration (S1) system of $54.2 \%>$ Ga-HSC (S2) system of $48.8 \%>$ the Ga-PStoICE (S4) system of $47.7 \%$. In general, MSW direct incineration system (S1) was found to be more energy efficient as compared to the gasification- based WtE technologies. The reason was the increased number of conversion steps for gasification-based systems (including MSW pretreatment, gasification, downstream energy utilization, and etc.), which leads to more energy losses and auxiliary consumptions. It was worth mentioning that the gasification-based S3 system describes CExC efficiency, which was mainly due to relatively high downstream electricity generation efficiency (from purified syngas to electricity, $35.5 \%$ ) and heat recovery from produced syngas that undergoes cooling down. On the contrary, gasification- based S4 system had the worst $\eta_{\mathrm{CExC}}$, which was because of lower electricity generation efficiency (25.0\%) and raw energy/materials consumed for the pretreatment of MSW (i.e. $100.0 \mathrm{kWh}$ of electricity for one tonne MSW). With recent technologies, $\eta_{\text {CExC }}$ of S2 was decreased by approximately $4.9 \%$ as compared to S1, indicating that the gasification-based two-steps combustion was not better than modern MSW direct incineration.

With regards to the CDP of the considered systems, similar changing tendency was observed by CExC efficiency. However, the value of $\mathrm{CDP}$ (within the range of $13.0 \%$ and $17.9 \%$ ) was found to be much lower than that of $\eta_{\mathrm{CEx}}$ (within the range of $47.7 \%$ and $64.4 \%)$. This CDP of the systems indicates that the consumed 

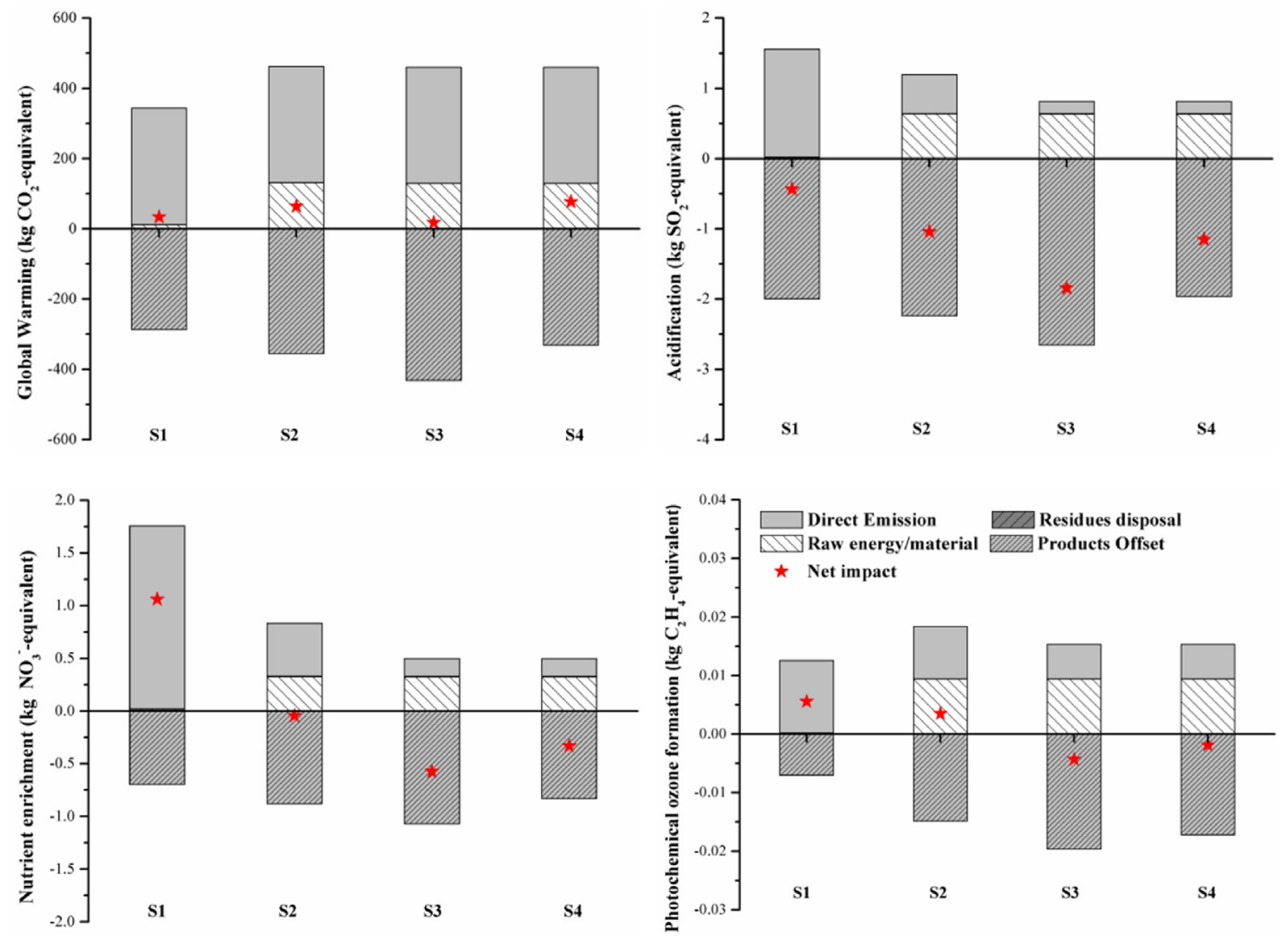

Fig. 2. Environmental impacts of the considered systems (S1: Direct incineration system; S2: Ga-HSC system; S3: Ga-PStoGT/CC system; and S4: Ga-PStoICE system).

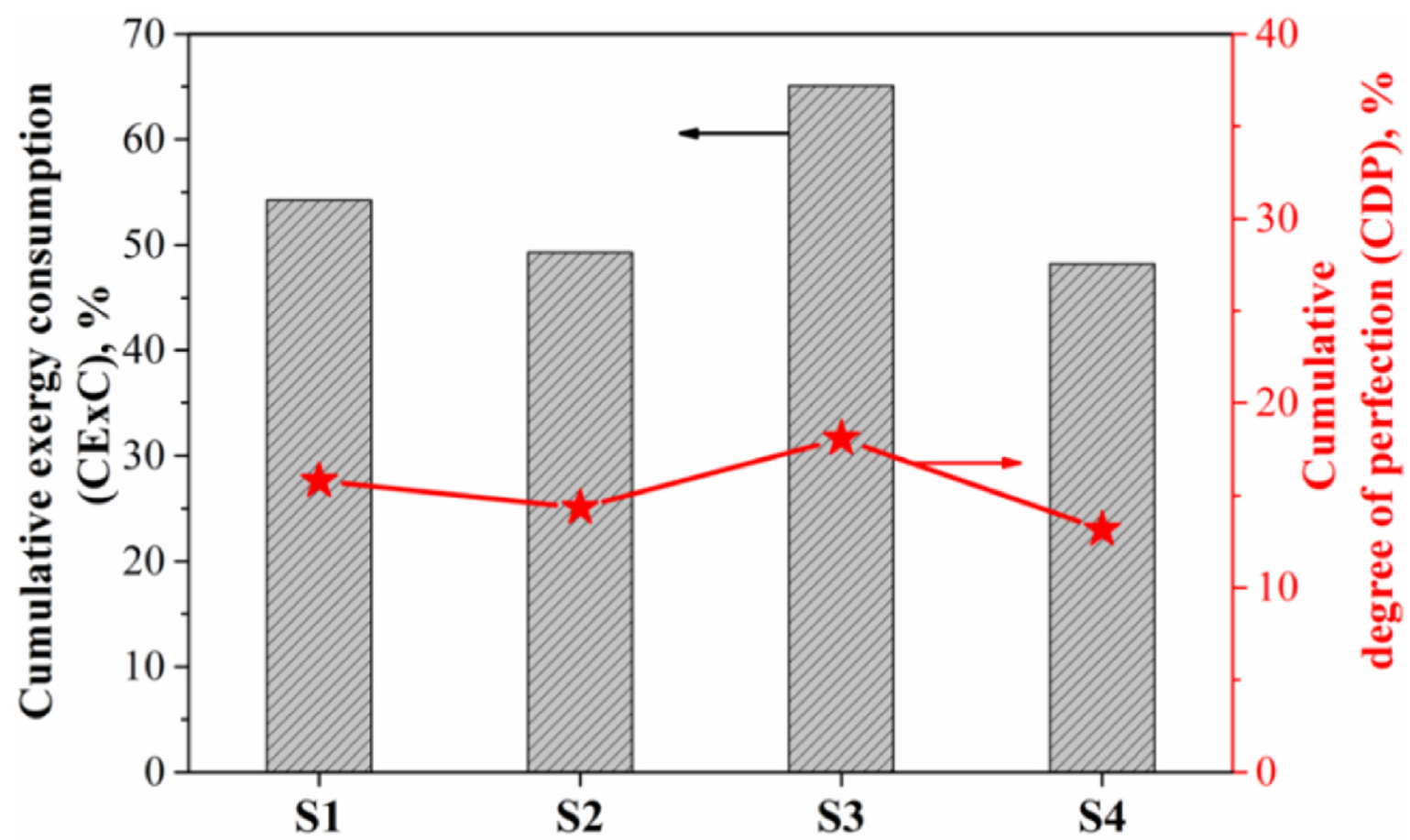

Fig. 3. Cumulative exergy consumption (CExC) efficiency ( $\eta_{\text {CExC }}$ ) and cumulative degree of perfection (CDP) of the systems. 
energy/materials derived from natural resources were recovered by the final products (electricity). The CExC efficiency was the ratio of the total amount of CExC of input and output streams, while the CDP represents the ratio of the chemical exergy of products over the total amount of CExC of input streams, so, the logic seems valid. The chemical exergy of the products was much lower than its CExC values. The brief comparisons of electricity generation process shows that the CDP of electricity production was estimated to be 29.1\% according to Table 5, which was much lower than its CExC efficiency estimated to be $100.0 \%$. Therefore, CDP indicated the thermodynamics perfection and the degree of the renewability of a system or a process and quantifies the energy utilization efficiency at a life cycle level.

Table 6 illustrated the total abatement exergy consumed for the treatment of emissions by each system. The abatement exergy for treating $1 \mathrm{~kg}$ of the emitted $\mathrm{CO}_{2}, \mathrm{SO}_{2}$ and $\mathrm{NO}_{\mathrm{x}}$ to an environmental acceptable level was estimated to be 5.9, 57.0 and 16.0 MJ, according to Dong et al. [19]. Unfortunately, abatement exergy loss caused by other emissions have not yet been found in literature [45]. Therefore, only a small part of abatement exergy loss was taken into account in this work. However, this method can be studied if relevant data would be identified in the future.

The total amount of abatement exergy loss was directly related with air emissions. Results revealed that S3 and S4 lead to the lowest abatement exergy loss, then S2, and S1 consumes the highest abatement exergy. It was somewhat different from the results of LCA, where the environmental impacts of S3 were lower than that of S4 for all the considered categories. The reasons have two aspects: first is, there were only few gaseous emissions considered in this work when calculating the abatement exergy, which was due to the limitation of the methodology. Therefore, the abatement exergy loss for the treatment of $\mathrm{CO}_{2}$ accounts for more than $97 \%$ of the total abatement exergy, due to the huge amount of $\mathrm{CO}_{2}$ emitted compared with $\mathrm{SO}_{2}$ and $\mathrm{NO}_{\mathrm{x}}$. This may cause misunderstandings, so abatement exergy method needs to be developed more for other pollutants, especially caused by hazardous emissions such as dioxins and heavy metals. The second aspect was that the abatement exergy loss considered only the emissions from the systems, while the results of LCA were the combination of the impacts caused by both direct emissions and credits from products.

Thus, by subtracting the abatement exergy loss from the output CExC flows, the AbatCExC efficiency of the systems was also calculated and presented in Table 5. The AbatCExC efficiency was declined comparative to CExC efficiency. However, the changing tendency was found to be similar.

\subsection{Comparisons and discussions}

The utilization of gasification technologies in MSW treatment

Table 6

The total abatement exergy loss of the considered systems.

\begin{tabular}{lllll}
\hline Systems & Emissions & Amount & Abatement exergy & AbatCExC efficiency \\
\hline $\mathrm{S} 1$ & $\mathrm{CO}_{2}$ & $331.3 \mathrm{~kg}$ & $1985.4 \mathrm{MJ}$ & $36.5 \%$ \\
& $\mathrm{SO}_{2}$ & $0.4 \mathrm{~kg}$ & & \\
& $\mathrm{NO}_{\mathrm{x}}$ & $1.3 \mathrm{~kg}$ & & \\
$\mathrm{~S} 2$ & $\mathrm{CO}_{2}$ & $331.4 \mathrm{~kg}$ & $1955.5 \mathrm{MJ}$ & $33.3 \%$ \\
& $\mathrm{SO}_{2}$ & $0.1 \mathrm{~kg}$ & & \\
& $\mathrm{NO}_{\mathrm{x}}$ & $0.4 \mathrm{~kg}$ & & $48.9 \%$ \\
$\mathrm{~S} 3$ & $\mathrm{CO}_{2}$ & $331.4 \mathrm{~kg}$ & $1949.0 \mathrm{MJ}$ & \\
& $\mathrm{SO}_{2}$ & $0.1 \mathrm{~kg}$ & & \\
& $\mathrm{NO}_{\mathrm{x}}$ & $0.1 \mathrm{~kg}$ & & $32.2 \%$ \\
$\mathrm{~S} 4$ & $\mathrm{CO}_{2}$ & $331.4 \mathrm{~kg}$ & $1949.0 \mathrm{MJ}$ & \\
& $\mathrm{SO}_{2}$ & $0.1 \mathrm{~kg}$ & & \\
& $\mathrm{NO}_{\mathbf{x}}$ & $0.1 \mathrm{~kg}$ & & \\
\hline
\end{tabular}

started from 1970s and had attracted more and more international concerns in recent year due to the demand of higher energy recovery efficiency and lower environmental emissions [20]. However, commercial applications of this kind of technology are still under exploration; further investigation is still essential. Based on the evaluation results from the present work, the gasificationbased gas turbine/combined cycle is the most promising alternative technology to achieve both environmental impacts reduction and energy recovery increment. The gasification-based WtE systems have alleviated the environmental burden regarding the impact categories of AC, NE and POF. However, the energy efficiency performances of the other two gasification-based systems were below expectations. It was also observed that although the downstream energy conversion efficiency of gasification-based two-step combustion could be higher than that of waste direct incineration, the overall energy conversion efficiencies may decrease, due to more complicated conversion steps and energy consuming.

A novel technology on basis of waste gasification and "two step" combustion was developed recently by the Lahti Energy Company in Kymijärvi II power plant in Finland [50-52]. In that plant, the produced raw syngas was cooled and purified before being sent to the second combustion chamber. Under such circumstance, contaminants, particularly chlorinated pollutants and solid particles were removed from the produced syngas in order to avoid the high temperature corrosion effects. The super-heated steam in the downstream boiler can reach to temperature of $540{ }^{\circ} \mathrm{C}$ and pressure of 12.1 MPa, which was considered to be much higher than adopted in waste incineration plants, typically at $400^{\circ} \mathrm{C}$ and $4.0 \mathrm{MPa}$ [34,53]. Therefore, higher energy conversion efficiency of the second step, from syngas to electricity, may be achieved under such scheme. However, due to unavailability of data, this kind of system was not evaluated in the present work, while further evaluation on this technology will be conducted in the future.

The effectiveness of the application of gasification-based technology in waste thermal treatment needs to be further investigated from both environmental performance and energy efficient aspect. Therefore, it is essential to conduct thorough and systematic evaluations of gasification-based MSW treatment technologies in the present work to provide valuable and scientific information and also to guide for future applications before it is launched in certain areas such as in China.

It is also noted that the use of the Lahti Energy scheme for downstream syngas pretreatment and energy conversion is also one route, that may lead to higher electricity generation efficiency of S2, resulting in better energy performance of "two-steps" conversion system. Therefore, appropriate combination of currently available best technologies (including waste pretreatment, thermal conversion, produced syngas purification, electricity generation and emission control) is of great importance for the commercial applications of gasification-based WtE systems.

\section{Conclusions}

In this study, four different MSW incineration- and gasificationbased WtE technologies have been modeled and compared from both environmental impacts and exergetic efficiency perspective using the methods of environmental life cycle assessment (LCA) and exergetic LCA (ELCA). Results revealed that the gasificationbased gas turbine/combined cycle system has exhibited the best environmental performance and highest cumulative exerfetic consumption (CExC) and cumulative degree of perfection (CDP) efficiencies among the considered systems. The gasification-based WtE technologies showed lower environmental impacts on the categories of acidification potential, nutrient enrichment potential, and photochemical ozone formation potential but caused higher 
global warming potential. The reason was mainly attributed to their higher overall electricity generation efficiencies and lower direct air emissions. ELCA results also indicated that the other two gasification-based WtE systems (S2 and S4) exhibited lower CExC and CDP efficiency than MSW direct incineration. The reason was mainly due to the increased conversion steps and more auxiliary consumptions for MSW pretreatment of gasification-based systems.

\section{Declaration of competing interest}

The authors declare that they have no known competing financial interests or personal relationships that could have appeared to influence the work reported in this paper.

\section{CRediT authorship contribution statement}

Yuanjun Tang: Conceptualization, Investigation, Methodology, Writing - original draft, Supervision. Jun Dong: Methodology, Writing - review \& editing. Guoneng Li: Funding acquisition. Youqu Zheng: Supervision, Funding acquisition, Writing - review \& editing. Yong Chi: Supervision, Funding acquisition. Ange Nzihou: Writing - review \& editing. Elsa Weiss-Hortala: Writing - review \& editing, Validation. Chao Ye: Validation.

\section{Acknowledgments}

The authors gratefully acknowledge the financial support from the key R\&D plan of Zhejiang Province, China (Grant no. 2020C03115), the National Natural Science Foundation of China (Grant no. 51676170, 51906220) and the Natural Science Foundation of Zhejiang Province, China (Grant no. LQ19E080002, LQ19E060002).

\section{References}

[1] Istrate I-R, García-Gusano D, Iribarren D, Dufour J. Long-term opportunities for electricity production through municipal solid waste incineration when internalising external costs. J Clean Prod 2019;215:870-7.

[2] Liu Y, Ni Z, Kong X, Liu J. Greenhouse gas emissions from municipal solid waste with a high organic fraction under different management scenarios. J Clean Prod 2017;147:451-7.

[3] Ye C, Wang Q, Zheng Y, Li G, Zhang Z, Luo Z. Techno-economic analysis of methanol and electricity poly-generation system based on coal partial gasification. Energy 2019;185:624-32.

[4] Zheng X, Ying Z, Wang B, Chen C. Hydrogen and syngas production from municipal solid waste (MSW) gasification via reusing CO2. Appl Therm Eng 2018;144:242-7.

[5] Yu H, Wu Z, Chen G. Catalytic gasification characteristics of cellulose, hemicellulose and lignin. Renew Energy 2018;121:559-67.

[6] Cao Y, Fu L, Mofrad A. Combined-gasification of biomass and municipal solid waste in a fluidized bed gasifier. J Energy Inst 2019;92(6):1683-8.

[7] Win MM, Asari M, Hayakawa R, Hosoda H, Yano J, Sakai S-i. Characteristics of gas from the fluidized bed gasification of refuse paper and plastic fuel (RPF) and wood biomass. Waste Manag 2019;87:173-82.

[8] Goulart Coelho LM, Lange LC. Applying life cycle assessment to support environmentally sustainable waste management strategies in Brazil. Resour Conserv Recycl 2018;128:438-50.

[9] Aryan Y, Yadav P, Samadder SR. Life Cycle Assessment of the existing and proposed plastic waste management options in India: a case study. J Clean Prod 2019:211:1268-83.

[10] Toniolo S, Mazzi A, Garato VG, Aguiari F, Scipioni A. Assessing the "design paradox" with life cycle assessment: a case study of a municipal solid waste incineration plant. Resour Conserv Recycl 2014;91:109-16.

[11] Viau S, Majeau-Bettez G, Spreutels L, Legros R, Margni M, Samson R. Substitution modelling in life cycle assessment of municipal solid waste management. Waste Manag 2020;102:795-803.

[12] Arena U, Ardolino F, Di Gregorio F. A life cycle assessment of environmenta performances of two combustion-and gasification-based waste-to-energy technologies. Waste Manag 2015;41:60-74.

[13] Evangelisti S, Tagliaferri C, Clift R, Lettieri P, Taylor R, Chapman C. Life cycle assessment of conventional and two-stage advanced energy-from-waste technologies for municipal solid waste treatment. J Clean Prod 2015;100: $212-23$.
[14] Portha J-F, Louret S, Pons M-N, Jaubert J-N. Estimation of the environmental impact of a petrochemical process using coupled LCA and exergy analysis. Resour Conserv Recycl 2010;54(5):291-8.

[15] Rocco MV, Di Lucchio A, Colombo E. Exergy life cycle assessment of electricity production from waste-to-energy technology: a hybrid input-output approach. Appl Energy 2017;194:832-44.

[16] Morosuk T, Tsatsaronis G, Koroneos C. Environmental impact reduction using exergy-based methods. J Clean Prod 2016;118:118-23.

[17] Wang S, Liu C, Liu L, Xu X, Zhang C. Ecological cumulative exergy consumption analysis of organic Rankine cycle for waste heat power generation. J Clean Prod 2019;218:543-54.

[18] Khandelwal H, Dhar H, Thalla AK, Kumar S. Application of life cycle assessment in municipal solid waste management: a worldwide critical review. J Clean Prod 2019;209:630-54.

[19] Dong J, Chi Y, Tang Y, Wang F, Huang Q. Combined life cycle environmental and exergetic assessment of four typical sewage sludge treatment techniques in China. Energy \& Fuels 2014;28(3):2114-22.

[20] Dong J, Tang Y, Nzihou A, Chi Y, Weiss-Hortala E, Ni M. Life cycle assessment of pyrolysis, gasification and incineration waste-to-energy technologies: theoretical analysis and case study of commercial plants. Sci Total Environ 2018;626:744-53.

[21] Lin X, Wang F, Chi Y, Huang Q, Yan J. Thermodynamic equilibrium analysis on limitation of moisture and ash for optimal air gasification of municipal solid waste. Waste and biomass valorization 2018;9(2):327-33.

[22] Kourkoumpas D-S, Karellas S, Kouloumoundras S, Koufodimos G, Grammelis P, Kakaras E. Comparison of waste-to-energy processes by means of life cycle analysis principles regarding the global warming potential impact: applied case studies in Greece, France and Germany. Waste and Biomass Valorization 2015;6(4):605-21.

[23] Dong J, Ni M, Chi Y, Zou D, Fu C. Life cycle and economic assessment of sourceseparated MSW collection with regard to greenhouse gas emissions: a case study in China. Environ Sci Pollut Control Ser 2013;20(8):5512-24.

[24] Morris M, Waldheim L. Energy recovery from solid waste fuels using advanced gasification technology. Waste Manag 1998;18(6):557-64.

[25] Upadhyay DS, Makwana HV, Patel RN. Performance evaluation of 10 kWe pilot scale downdraft gasifier with different feedstock. J Energy Inst 2019;92(4): 913-22.

[26] Aydin ES, Yucel O, Sadikoglu H. Experimental study on hydrogen-rich syngas production via gasification of pine cone particles and wood pellets in a fixed bed downdraft gasifier. Int J Hydrogen Energy 2019;44(32):17389-96.

[27] Mazzoni L, Almazrouei M, Ghenai C, Janajreh I. A comparison of energy recovery from MSW through plasma gasification and entrained flow gasification. Energy Procedia 2017;142:3480-5.

[28] Wan C, Yu F, Zhang Y, Li Q, Wooten J. Material balance and energy balance analysis for syngas generation by a pilot-plant scale downdraft gasifier. J Biobased Mater Bioenergy 2013;7:690-5.

[29] Abdoulmoumine N, Kulkarni A, Adhikari S. Effects of temperature and equivalence ratio on mass balance and energy analysis in loblolly pine oxygen gasification. Energy Science \& Engineering 2016;4(4):256-68.

[30] Francois J, Abdelouahed L, Mauviel G, Patisson F, Mirgaux O, Rogaume C, et al, Detailed process modeling of a wood gasification combined heat and power plant. Biomass Bioenergy 2013;51:68-82.

[31] Arena U, Di Gregorio F. Gasification of a solid recovered fuel in a pilot scale fluidized bed reactor. Fuel 2014;117:528-36.

[32] Jordan CA, Akay G. Effect of $\mathrm{CaO}$ on tar production and dew point depression during gasification of fuel cane bagasse in a novel downdraft gasifier. Fuel Process Technol 2013;106:654-60.

[33] Arena U. Process and technological aspects of municipal solid waste gasification. A review. Waste management. 2012;32(4):625-39.

[34] Consonni S, Viganò F. Waste gasification vs. conventional Waste-To-Energy: a comparative evaluation of two commercial technologies. Waste Manag 2012;32(4):653-66.

[35] Worapot Ngamchompoo KT. Quality enhancement of producer gas from cassava rhizome using high temperature air-steam downdraft gasification. Am J Appl Sci 2013;10(4):395-402.

[36] Situmorang Y, Zhao Z, Yoshida A, Kasai Y, Abudula A, Guan G. Potential power generation on a small-scale separated-type biomass gasification system. Energy 2019;179:19-29.

[37] Werle S, Sobek S. Gasification of sewage sludge within a circular economy perspective: a Polish case study. Environ Sci Pollut Control Ser 2019;26(35): $35422-32$.

[38] Soni V, Naik V. Gasification-A process for energy recovery and disposal of municipal solid waste. American Journal of Modern Energy 2016:2(6):38-42.

[39] Belgiorno V, De Feo G, Della Rocca C, Napoli R. Energy from gasification of solid wastes. Waste Manag 2003;23(1):1-15.

[40] China State Environmental Protection Administration. China pollution control standard for MSW incineration (GB18485-2014). Beijing: Chinese Environmental Science Press; 2014.

[41] China State Environmental Protection Administration. China emission standard of air pollutants for thermal power plants (GB 13223-2011). Beijing: Chinese Environmental Science Press; 2011.

[42] Cong L, Guo G, Yu M, Yang F, Tan L. The energy consumption and emission of Polyurethane pavement construction based on life cycle assessment. J Clean Prod 2020:120395.

[43] Szargut J, Morris DR. Cumulative exergy consumption and cumulative degree 
of perfection of chemical processes. Int J Energy Res 1987;11(2):245-61.

[44] Cornelissen RL. Thermodynamics and sustainable development: the use of exergy analysis and the reduction of irreversibility. Universiteit Twente; 1997.

[45] Stougie L, Tsalidis GA, van der Kooi HJ, Korevaar G. Environmental and exergetic sustainability assessment of power generation from biomass. Renew Energy 2018;128:520-8.

[46] Stougie L, Giustozzi N, van der Kooi H, Stoppato A. Environmental, economic and exergetic sustainability assessment of power generation from fossil and renewable energy sources. Int J Energy Res 20;42:2916-26.

[47] Yang Q, Chen B, Ji X, He Y, Chen G. Exergetic evaluation of corn-ethanol production in China. Commun Nonlinear Sci Numer Simulat 2009;14: 2450-61.

[48] Di X, Nie Z, Yuan B, Zuo T. Life cycle inventory for electricity generation in China. Int J Life Cycle Assess 2007;12(4):217-24.
[49] Dewulf J, Van Langenhove H, Dirckx J. Exergy analysis in the assessment of the sustainability of waste gas treatment systems. Sci Total Environ 2001;273(1) $41-52$.

[50] Hognert J, Nilsson L. The small-scale production of hydrogen, with the coproduction of electricity and district heat, by means of the gasification of municipal solid waste. Appl Therm Eng 2016;106:174-9.

[51] Bolhar-Nordenkampf M, Isaksson J. Operating experiences of large scale CFBgasification plants for the substitution of fossil fuels. Conference Operating experiences of large scale CFB-gasification plants for the substitution of fossil fuels.

[52] Energia Lahti. https://www.lahtienergia.fi/fi.

[53] Bianchi M, Branchini L, De Pascale A. Combining waste-to-energy steam cycle with gas turbine units. Appl Energy 2014;130(Supplement C):764-73. 